\title{
Effect of direct current on gas condensate droplet immersed in brine solution
}

\author{
Princewill M. Ikpeka ${ }^{1,2}\left(\mathbb{D} \cdot\right.$ Johnson O. Ugwu ${ }^{1}\left(\mathbb{0} \cdot\right.$ Gobind G. Pillai $^{1}\left(\mathbb{1} \cdot\right.$ Paul Russell $^{1}$
}

Received: 2 January 2021 / Accepted: 6 May 2021 / Published online: 22 May 2021

(c) The Author(s) 2021

\begin{abstract}
Environmentally sustainable methods of extracting hydrocarbons from the reservoir are increasingly becoming an important area of research. Several methods are being applied to mitigate condensate banking effect which occurs in gas condensate reservoirs; some of which have significant impact on the environment (subsurface and surface). Electrokinetic enhanced oil recovery (EEOR) increases oil displacement efficiency in conventional oil reservoirs while retaining beneficial properties to the environment. To successfully apply this technology on gas condensate reservoirs, the behavior of condensate droplets immersed in brine under the influence of electric current need to be understood. A laboratory experiment was designed to capture the effect of electrical current on interfacial tension and droplet movement. Pendant drop tensiometry was used to obtain the interfacial tension, while force analysis was used to analyze the effect of the electrical current on droplet trajectory. Salinity (0-23 ppt) and electric voltage (0-46.5 V) were the main variables during the entire experiment. Results from the experiment reveal an increase in IFT as the voltage is increased, while the droplet trajectory was significantly altered with an increase in voltage. This study concludes that the interfacial tension increases progressively with an increase in DC current, until its effect counteracts the benefit obtained from the preferential movement of condensate droplet.
\end{abstract}

Keywords Interfacial Tension · Pendant Drop Tensiometry · Droplet Rise Velocity · Gas Condensate

\section{Introduction}

In gas condensate reservoirs, reservoir fluids exist initially in gaseous phase but as the reservoir pressure declines below the dew point pressure, liquids condense out of the gaseous phase. As observed in the temperature-pressure phase envelope shown in Fig. 1, gas condensate reservoirs have a temperature range greater than the critical temperature but less than the Cricondentherm (maximum temperature

Princewill M. Ikpeka

P.ikpeka@tees.ac.uk; Princewill.ikpeka@futo.edu.ng

Johnson O. Ugwu

J.ugwu@tees.ac.uk

Gobind G. Pillai

G.G.Pillai@tees.ac.uk

Paul Russell

p.russell@tees.ac.uk

1 School of Computing Engineering and Digital Technologies, Teesside University, Middlesbrough, UK

2 Department of Petroleum Engineering, Federal University of Technology, Owerri, Nigeria for which two phases can exist). Gas condensate reservoirs produce both gaseous and liquid condensates on the surface separators (Louli et al. 2012; Majidi et al. 2014; Skylogianni et al. 2015). As the initial pressure of the reservoir (indicated by point $\mathrm{A}$ on the phase envelope), declines isothermally to a condition below the dew-point curve (indicated by point $\mathrm{B}$ on the envelope), heavier fraction of the reservoir fluids condenses out of the gas phase. More liquid condenses out as the reservoir pressure decreases beyond the dew point (Almehaideb et al. 2003; Mohammadi et al. 2013; Mokhtari et al. 2013; Novak et al. 2018).

The liquid condensate forms a "ring" or "bank" around the production wells as shown in Fig. 2. This phenomenon is commonly referred to as condensate banking (Barker 2005; Hassan et al. 2019; Rahimzadeh et al. 2016). Within the reservoir pore space, the condensate bank remains immobile until its saturation exceeds critical saturation $\left(S_{\mathrm{cc}}\right)$. The formation of the condensate bank around the producing well decreases the cross-sectional area available for gas flow, consequently reducing the gas production rate. From the literature reviewed, there are two main approaches to managing gas condensate banks; (i) modeling reservoir performance 


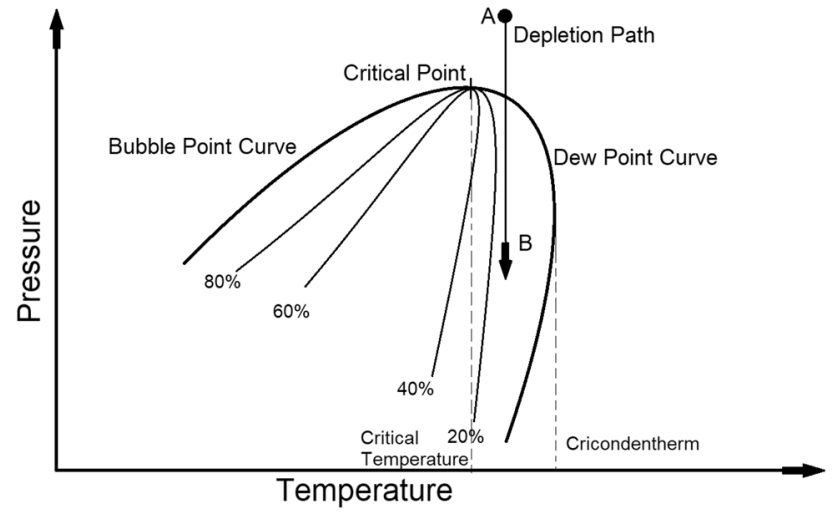

Fig. 1 Gas condensate phase envelope

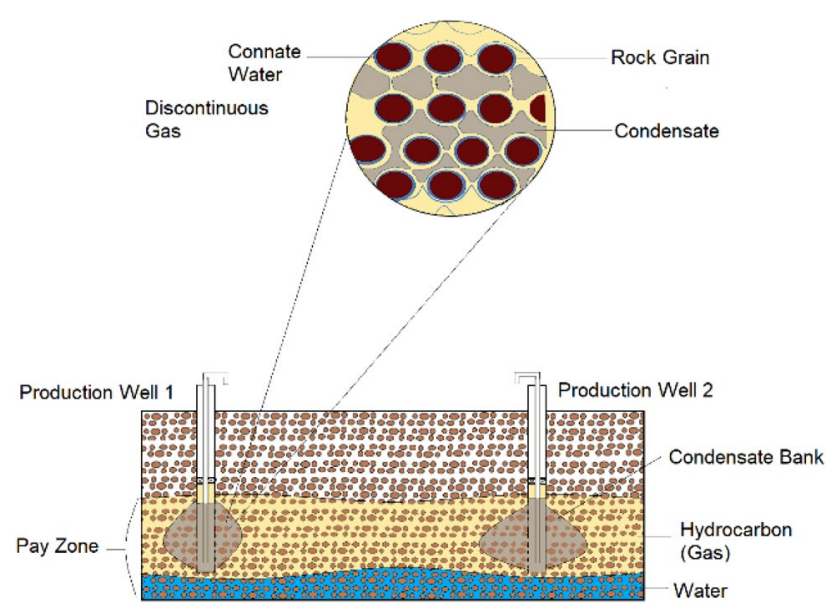

Fig. 2 Schematics of gas condensate banking (Ikpeka et al. 2020)

to predict/delay the onset of the banking, and (ii) mitigating gas condensate blockage already formed using chemical/mechanical methods. This study focuses on the second approach.

Several techniques have been applied to mitigate gas condensate banking effect. One of such techniques involves the injection of solvents and alcohols such as Methanol to reduce the interfacial tension between the heavier liquid fractions and the lighter gaseous fractions (Azari et al. 2018; Cameselle and Gouveia 2018; Hassan et al. 2019). When interfacial tension is reduced between the gaseous and liquid phases, the displacement efficiency of the injected brine or gas is remarkably improved. However, this technique only provides temporary relief to the production wells. As production continues overtime, the effect of the solvent wears out and more solvents/ alcohols is required to be injected. Besides the cost of injecting the solvents into the well, the periodic shutting of the production well comes at a cost to the production company. The cost-benefit ratio of this method depends primarily on the volume and cost of Solvents/Methanol injected compared to the equivalent amount of gas produced within the time frame. An important limitation of this technique is that some reservoir clay fines and formation water is sensitive to Methanol (Al-Anazl et al. 2005). Another technique employed to mitigate condensate banking is wettability alteration of reservoir rock from water wet to preferentially gas wet using surfactant flooding, polymer flooding and nanoparticles (Fahimpour and Jamiolahmady 2014; Hassan et al. 2019; Williams and Dawe 1989). This technique results in a permanent alteration of the reservoir pore structure; permeability, and porosity. The consequence of this alteration could be severe pore throat blockage and irreversible well damage (Babadagli 2007; Dang et al. 2018; Gregersen et al. 2013). The permeability of condensate-banked region can be improved by dissolving carbonaceous materials in sandstone reservoirs through acidizing (Ansari et al. 2015a, 2017; Rossen et al. 1995; Tang \& Morrow 1999). High temperature affects the effectiveness of acids and surfactants in both carbonate and sandstone reservoirs. At higher reservoir temperatures, acids react quickly with the sandstone and this limits its ability to penetrate the formation. A further technique used to mitigate condensate banking is gas injection and water-alternatinggas injection to maintain reservoir pressure above dew point pressure (Geiger et al. 2009; Hassan et al. 2019; Rossen et al. 1995; van Dijke and Sorbie 2003). While authors have investigated the use of different types of gas for re-injection purposes (Ayub and Ramadan 2019; Odi et al. 2012), for the gas re-injection to be effective, it has to be above the minimum miscibility pressure and the injected gas should be easily separated from the reservoir fluids at the surface (Ayub and Ramadan 2019; Dang et al. 2018; Garmeh et al. 2009; Hoteit 2013). However, for this method to be effective, the amount of gas injected into the reservoir must equal or be greater than the hydrocarbon produced from the reservoir (Sayed and Al-Muntasheri 2016). This presents an important limitation for this technique in the long term. An alternative technique for mitigating the effect of condensate banking involves drilling horizontal wells and hydraulic fracturing. However, this technique delays the onset of condensate banking and does not stop its occurrence (Behmanesh et al. 2018; Ghahri et al. 2018; Ghahri 2010; Hassan et al. 2019; Hekmatzadeh and Gerami 2018; Wei Zhang et al. 2019a, b). Hydraulic fracturing if not properly cleaned up can accumulate liquid within the fractures which affects the efficiency of the technique. In addition to these, the operational cost is sometimes very high and could be as much as several million dollars in the case of drilling horizontal wells (Hassan et al. 2019).

The use of electric current in facilitating the flow of condensate in a reservoir presents an interesting solution to treating condensate banking (Rehman \& Meribout 2012). Previous laboratory studies done on conventional reservoirs 
have shown significant improvement in oil recovery when direct current is passed through the core samples (Ansari et al. 2015b; Ghosh et al. 2012; Hill 2014; Yim et al. 2017; Wentong Zhang et al. 2019a, b). Numerical investigation conducted by Peraki et al. (2018) reported an increase in oil recovery when electric current is combined with waterflooding. The improved recoveries observed in these studies were attributed to electrical double layer expansion of oil-brinerock interface, movement of charged ions from the anode to the cathode, drag-force transfer of water molecules associated with charged ion movement, disintegration of water molecules into constituent gaseous and ionic phases, movement of colloid particles, viscosity reduction and thermal mobility of reservoir fluid (Ghazanfari et al. 2012; Haroun et al. 2009; Peraki et al. 2018; Wittle et al. 2011). Some factors affecting the efficiency of EEOR in oil reservoirs include brine salinity, hydrocarbon composition (presence of polar components as found in asphaltenes), rock mineral composition and the amount of direct current passed through the reservoir. Within the pore space of gas condensate reservoirs, formation brine containing dissolved minerals and condensate molecules (in gaseous or liquid state depending on the pressure condition) interacts with the minerals of pore walls. Direct current introduced into this pore space interacts with the brine, condensate, and surface of the pore walls. These interactions support the hydrodynamic condition of the reservoir to yield more condensate. Previous studies conducted macro-experiments using direct current on core samples saturated with brine. These experiments do not capture the interactions within the pore space. To adequately quantify the effect of electric current on gas condensate reservoirs, these interactions need to be characterized. This study attempts to capture the behavior of condensate droplet in the presence of electric current in real-time. The effect of electric current of condensate droplets is captured vis-à-vis interfacial tension changes and movement of droplets due to electric field.

\section{Interfacial tension calculation (Pendant drop method)}

In hydrocarbon recovery, a lower IFT improves the sweep efficiency of the water flood and favors recovery of more oil (Asar \& Handy 1989; Thomas et al. 2009; Wagner and Leach 1966). There are many techniques available to measure interfacial tension in a fluid-fluid system and their features are described by Drelich et al. 2002. In this study, Pendant drop tensiometry (PDT) was used because of its simplicity and robustness. In PDT, the shape of the droplet is used to estimate the interfacial tension of the fluid (Berry et al. 2015; Ferri and Fernandes 2011; Loglio et al. 2011). By extracting the dimensions of the condensate droplet, the interfacial tension can be estimated using the dimensionless shape factor as captured in Fig. 3 (Drelich 2002; Stauffer 1965). The equatorial diameter of the droplet $D$, and the diameter $d$, at a distance $D$ from the tip of the droplet are all measured. The dimensions are taken just before droplet breaks-off to ensure a maximum $D$.

The interfacial tension is then calculated from the following equation:

$\gamma=\frac{\Delta \rho g D^{2}}{H}$

$\frac{1}{H}=\frac{B_{4}}{S^{a}}+B_{3} S^{3}-B_{2} S^{2}+B_{1} S-B_{0}$

$S=\frac{d}{D}$

where

$B_{\mathrm{i}}$-constants.

$\mathrm{H}$-Shape dependent parameter.

The range of $\mathrm{S}$ is shown in Table 1

\section{Condensate droplet rise trajectory}

The condensate droplet rises vertically through the brine solution in the absence of electric current. Figure 4 traces the droplet rise trajectory path through the brine solution. The velocity of the vertical rise is dependent on the temperature, salinity of the surrounding brine and composition of the condensate droplet. However, in the presence of electric field, the droplet exhibits a preferential movement toward the cathode. At position $A$, after droplet break-up, the droplet rises vertically because the dominant force acting immediately is

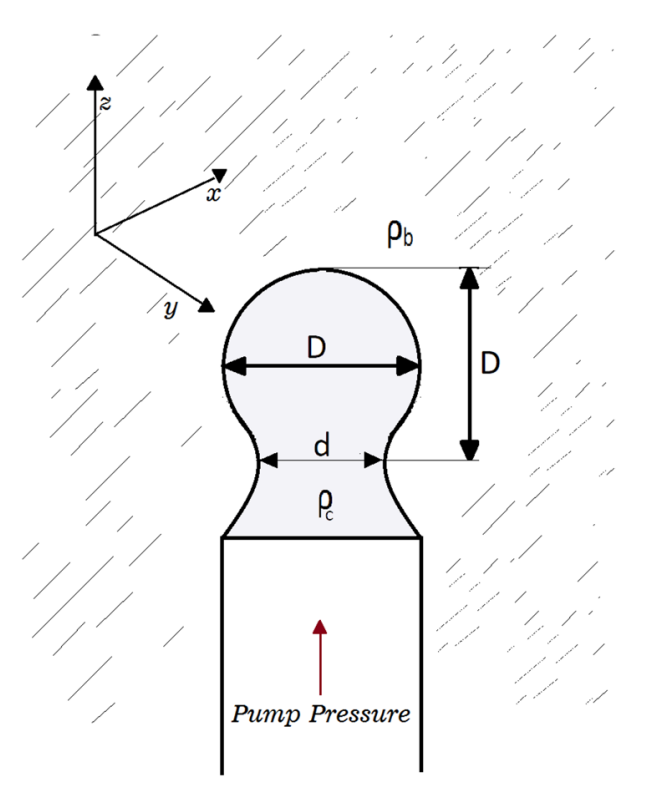

Fig. 3 Estimating interfacial tension using Pendant drop method 
Table 1 Empirical constants for Eq. (1) (Drelich 2002)

\begin{tabular}{rlllrrl}
\hline Range of $\mathrm{S}$ & $\mathrm{A}$ & $\mathrm{B}_{4}$ & $\mathrm{~B}_{3}$ & $\mathrm{~B}_{2}$ & $\mathrm{~B}_{1}$ & \multicolumn{1}{c}{$\mathrm{B}_{0}$} \\
\hline $0.401-0.46$ & 2.56651 & 0.3272 & 0 & 0.97553 & 0.84059 & 0.18069 \\
$0.46-0.59$ & 2.59725 & 0.31968 & 0 & 0.46898 & 0.50059 & 0.13261 \\
$0.59-0.68$ & 2.62435 & 0.31522 & 0 & 0.11714 & 0.15756 & 0.05285 \\
$0.68-0.90$ & 2.64267 & 0.31345 & 0 & 0.09155 & 0.14701 & 0.05877 \\
$0.90-1.00$ & 2.84636 & 0.30715 & -0.69116 & -1.08315 & -0.18341 & 0.2097 \\
\hline
\end{tabular}

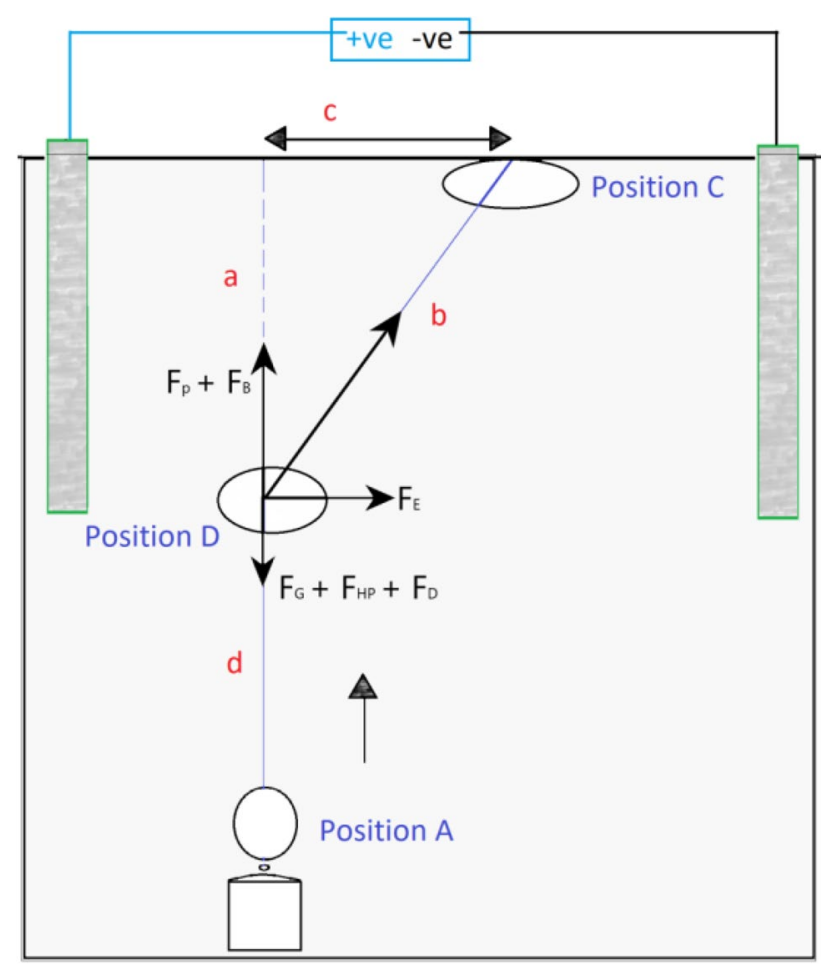

Fig. 4 Schematics of forces acting on Condensate droplet

buoyancy and pump pressure force. As the travel distance increases, the effect of electric field becomes increasingly dominant and causes a deviation in the otherwise straight path of the droplet. The point of deviation is marked by point $D$ while the distance traveled from point $A$ to $D$ is represented by $d$. At position $C$, the rising droplet reaches the surface of brine solution at a horizontal distance $c$ from the vertical point. Higher electric current applied in the system causes an equivalent higher deviation in $c$ (Fig. 5).

To define the effect of electric current on the condensate droplet, analyzing the dynamic forces acting on the droplet between both phases becomes necessary. Six main forces were identified to act on the condensate droplet as it rises through the continuous brine solution. These forces have been categorized below:

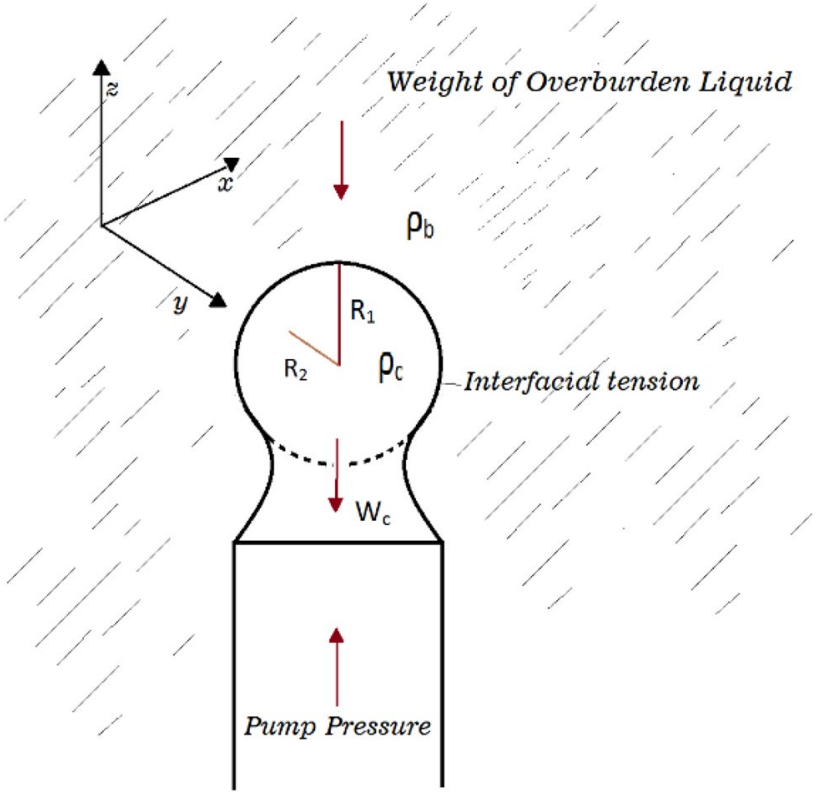

Fig. 5 Schematics of droplet interface and volume

\section{Upward acting forces}

1. Buoyancy force, $F_{B}$-For a system with constant brine salinity and pump flowrate, the buoyancy of the droplet can be estimated using Eq. (2). The volume of displaced brine is equivalent to the volume of condensate droplet. Assuming a fixed volume of droplet, the buoyancy force would be only a function of the salinity of the brine solution.

$F_{B}=V_{d} \rho_{b} g$

where $V_{d}$-droplet volume $\left(\mathrm{m}^{3}\right), \rho_{b}$-brine density $(\mathrm{kg} /$ $\left.\mathrm{m}^{3}\right), g$-gravity $\left(9.81 \mathrm{~m} / \mathrm{s}^{2}\right)$.

2. Pump pressure force, $F_{P \_}$Pump pressure force is given by the volumetric flowrate of the pump and is a function of time and is given by Eq. (3).

$F_{P}=Q_{p} \rho_{c} g$

where $Q_{p}$-volumetric flowrate $(\mathrm{m} 3 / \mathrm{s}), \rho_{c}$-condensate density $\left(\mathrm{kg} / \mathrm{m}^{3}\right)$. 


\section{Downward acting forces}

3. Gravity of the droplet, $F_{G-}$ The effect of gravity on the droplet is a function of the mass of condensate trapped within the droplet and is given by Eq. (4).

$F_{P}=V_{d} \rho_{c} g$

4. Hydrostatic Pressure Force, $F_{\mathrm{HP} \_ \text {Hydrostatic Pressure }}$ force of the brine column above the droplet is a function of droplet rise velocity and the weight of brine column above the droplet. It is a function of time and given by Eq. (5);

$F_{\mathrm{HP}}=V_{t} \rho_{b} g$

where $V_{t}$-Droplet rise velocity.

5. Drag force, $F_{D \_}$The empirical correlation given by (Kelbaliyev and Ceylan 2007) is used to estimate the drag coefficient. This correlation applies for $0.1 \leq \operatorname{Re}<0.5$ and it is presented in Eq. (6).

$F_{D}=C_{d} A \frac{\rho V_{t}^{2}}{2}, C_{d}=\frac{8}{\operatorname{Re}}\left[1+\frac{1}{1-0.5\left(1+250 \mathrm{Re}^{2}\right)^{-2}}\right]$

$C_{d}$-Drag coefficient.

$A$-surface area of droplet.

Re-Reynolds Number.

Assuming a constant surface area of droplet the Drag force is calculated as a function of droplet rise velocity.

\section{Lateral forces}

1. Electric force, $F_{E-}$ Coulomb's force of attraction between two charges is used to estimate the force attraction between the droplet and the anode. The magnitude of the force of attraction is shown in Eq. (7);

$F_{E}=\frac{1}{4 \pi \varepsilon_{o}} \frac{Q_{1} Q_{2}}{r^{2}}$

where $Q 1$-charge on the anode, $Q 2$-droplet charge, $r$-distance between droplet and anode, $\varepsilon_{0}$-permittivity of the medium.

The resultant force acting on the droplet is calculated from

$R=\sqrt{\left(F_{B}+F_{P}-F_{G}-F_{\mathrm{HP}}-F_{D}\right)^{2}+\left(F_{E}-F_{\mathrm{DE}}\right)^{2}}$,

$\theta=\tan ^{-1}\left(\frac{F_{B}+F_{P}-F_{G}-F_{\mathrm{HP}}-F_{D}}{F_{E}-F_{\mathrm{DE}}}\right)$

Analytical models are used to obtain $F_{B}, F_{P}, F_{G}, F_{\mathrm{HP}}, F_{D}$ and $F_{\mathrm{DE}}$, while $R$ is obtained from experimental data. Force due to electric field $F_{E}$ is then obtained by substitution of Eq. (8).

Assumptions for analytical models.

The following underlying assumptions were made during the development of the analytical models.

(i) Brine density is homogenous, and the brine volume is constant within the tank

(ii) There is negligible movement of particles within the brine

(iii) Droplet volume is constant during droplet rise

(iv) The temperature of the brine is constant throughout the experiment

(v) The graphite electrodes have constant surface charge

\section{Estimating droplet volume using Young-Laplace model}

Volume of droplet was calculated using Young-Laplace solution:

$\gamma\left(\frac{1}{R_{1}}+\frac{1}{R_{2}}\right)=\Delta P \equiv \Delta P_{0}-\Delta \rho g z$

$R_{1}$ and $R_{2}$ are the principal radii of curvature, while $\Delta P$ represents the pressure difference between the fluid within the droplet and the bulk continuous fluid outside the droplet. $\Delta \rho$ is the difference in densities of condensate fluid and brine solution. For an axisymmetric system, Eq. (9) can be written using cylindrical coordinate's $r, \phi$ and $z$ as presented by Karbaschi et al. 2015;

$\frac{\mathrm{d} \varphi}{\mathrm{d} s}=2-\frac{\Delta \rho g z R_{0}^{2}}{\gamma}-\frac{\sin \varphi}{r}$

$\frac{\mathrm{d} r}{\mathrm{~d} s}=\cos \varphi$

$\frac{\mathrm{d} z}{\mathrm{~d} s}=\sin \varphi$

The droplet profile of the experimental image is first extracted using canny edge detector (Canny 1986). Then the Laplace-young model is iteratively optimized to fit the extracted profile as described by (Berry et al. 2015). After fitting the droplet profile into the Young-Laplace equation as shown in Fig. 6, the volume and surface area of the droplet is estimated using Eq. (11).

$V_{d}=\pi \int r^{2} \sin \varphi \mathrm{d} s$

$A_{d}=2 \pi \int r \mathrm{~d} s$ 
Fig. 6 Processing experimental image to obtain droplet volume by fitting Young-Laplace equation

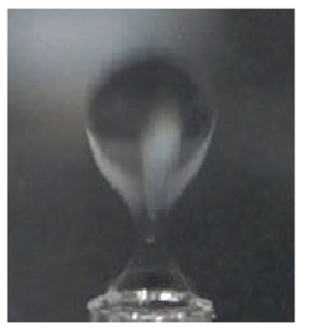

Image from experiment

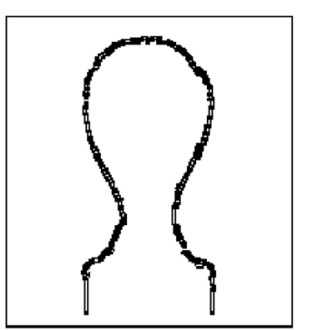

Edge Points extracted

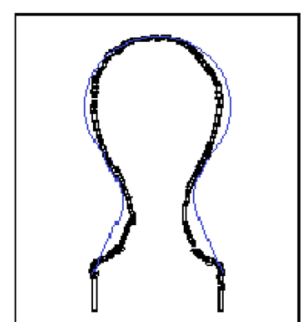

Initial guess using

Young-Laplace Equation

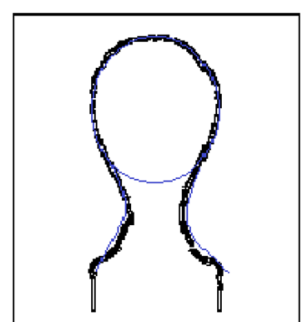

Fitted Model using

Iterative optimization

\section{Experimental investigation}

The experimental set-up shown in Fig. 7 is used to analyze the effect of direct current on droplets of the synthetic condensate rising through brine solution. The brine-condensate system is contained within a rectangular tank of dimensions: $36 \times 23 \times 26 \mathrm{~cm}$. The rectangular tank is made from $5 \mathrm{~mm}$ thick clear glass to allow for optical access into the system. The entire experiment was run under ambient temperature conditions. A variable rate syringe pump fitted with a partially filled $100 \mathrm{ml}$ Luer-locked graduated syringe is attached to $80 \mathrm{~cm}$ long clear flexible plastic tubing. The tubing is connected to a nozzle attached to the base of the tank. The position of the nozzle-tip is perpendicular to the base of the tank to ensure vertical release of droplets. A constant pump pressure is applied to the syringe pump.

Droplet movement is captured by a high-speed highresolution camera (DSC-RX10M3) with a total bit rate of $51195 \mathrm{kbps}$ and 50 frames per second. The camera is positioned perpendicular to tank so that the entire droplet path can be captured. A focused light source is attached at the opposite end of the tank to illuminate the droplet. A video processing tool (Adobe Photoshop 2020) is used to render the video into images at $40 \mathrm{fps}$. From the processed image, the effect of electric current on the droplet velocity was obtained.

\section{Synthetic condensate and brine preparation}

To prepare the synthetic condensate, n-pentane, n-hexane, $\mathrm{n}$-heptane, $\mathrm{n}$-octane, $\mathrm{n}$-decane, and toluene all of $99 \%$ purity were obtained from VWR Chemicals UK. Using n-pentane as the base fluid, other components were added under standard conditions of temperature and pressure according to the composition given in Table 2. To achieve homogenity, the resulting synthetic condensate was stirred continuously for $4 \mathrm{~h}$ using a table-mounted electric stirrer.

The brine composition was modeled after Kester et al., (1967). To prepare the brine solution, each salt component was first measured-out according to the composition given in Table 2. An empty beaker filled with $1400 \mathrm{~mL}$ of deionized water (density $0.9982 \mathrm{~g} / \mathrm{cm} 3 @ 20 \mathrm{oC}$ ) was placed on a table-mounted magnetic stirrer. The measured-out salts were

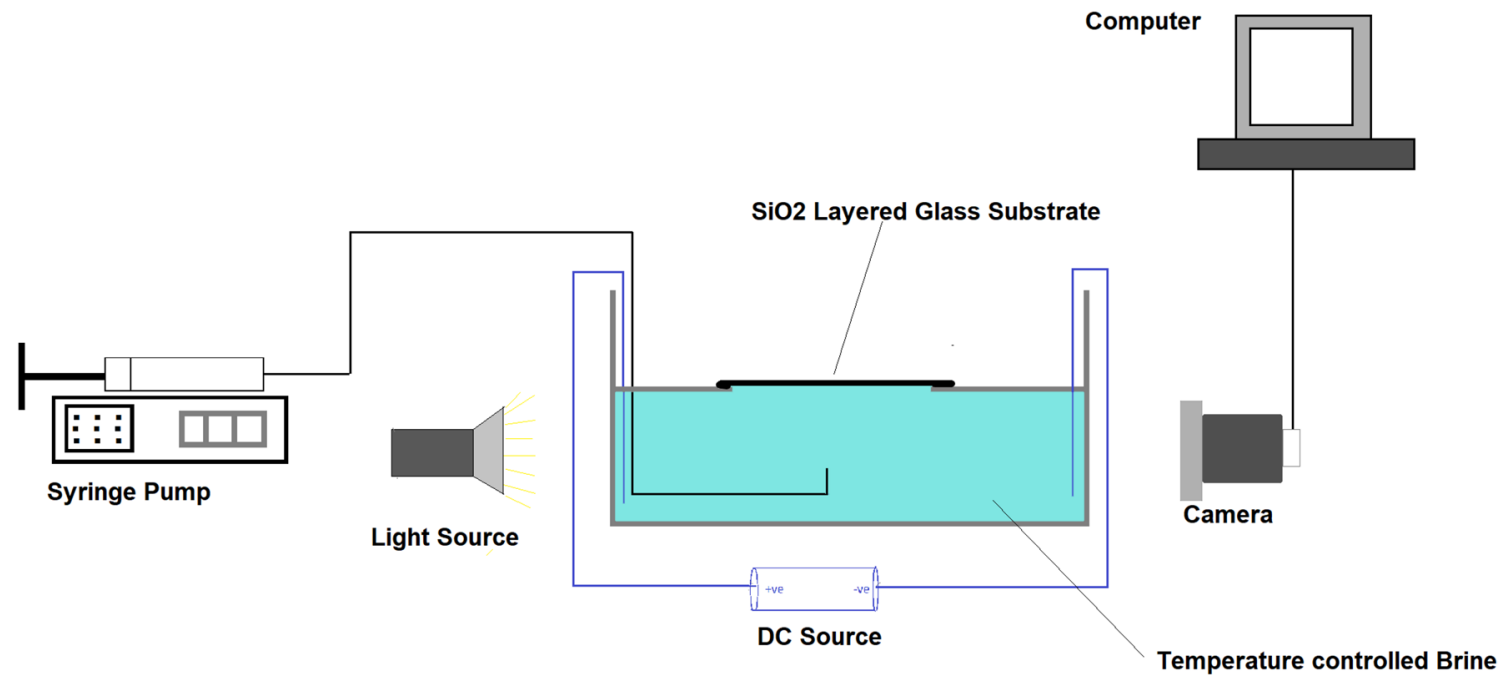

Fig. 7 Experimental Set-up 
Table 2 Brine and Condenstate composition

\begin{tabular}{lll}
\hline Fluid type & Component & Mass $(\mathrm{g})$ \\
\hline Condensate mixture & $\mathrm{C}_{5} \mathrm{H}_{12}$ & 112.5 \\
& $\mathrm{C}_{6} \mathrm{H}_{14}$ & 19.65 \\
$\mathrm{C}_{7} \mathrm{H}_{16}$ & 20.52 \\
& $\mathrm{C}_{8} \mathrm{H}_{18}$ & 21.09 \\
& $\mathrm{C}_{10} \mathrm{H}_{22}$ & 22.5 \\
& $\mathrm{C}_{7} \mathrm{H}_{8}$ & 4.335 \\
Brine salt solution & $\mathrm{NaCl}$ & 133.9856 \\
& $\mathrm{Na}_{2} \mathrm{SO}_{4}$ & 22.6041 \\
& $\mathrm{KCl}$ & 3.8029 \\
& $\mathrm{NaHCO}_{3}$ & 1.1109 \\
& $\mathrm{MgCl}_{2} \cdot 6 \mathrm{H}_{2} \mathrm{O}$ & 60.4232 \\
& $\mathrm{CaCl}_{2} \cdot 2 \mathrm{H}_{2} \mathrm{O}$ & 8.7345 \\
& $\mathrm{H}_{2} \mathrm{O}$ & 1400 \\
\hline
\end{tabular}

then added in the order shown in Table 2. To ensure homogeneity in the brine solution, each salt was added while stirring continuously for $10 \mathrm{~min}$ before the next was added. The mixing process is carried out with Steinberg Electric Stirrer with maximum rotation speed of $3400 \mathrm{rpm}$. The surface of the brine exposed to ambient temperature $\left(\sim 21^{\mathrm{O}} \mathrm{C} \pm 0.5\right)$ and atmospheric pressure (14.696 psi). The total volume of brine solution recorded was $1530 \mathrm{~mL}$, while the density of the brine was measured to be $1.0658 \mathrm{~g} / \mathrm{cm} 3$ and the Molarity was calculated to be $0.052 \mathrm{M}$. The actual experiment set-up is shown in Fig. 8. To prevent redox reactions at the electrodes during experiment, the graphite electrodes (with $99 \%$ percent purity) were used for both the cathode and anode. The graphite electrodes were connected to the power supply unit Powerflex CPX400A Dual 60 V 20A.

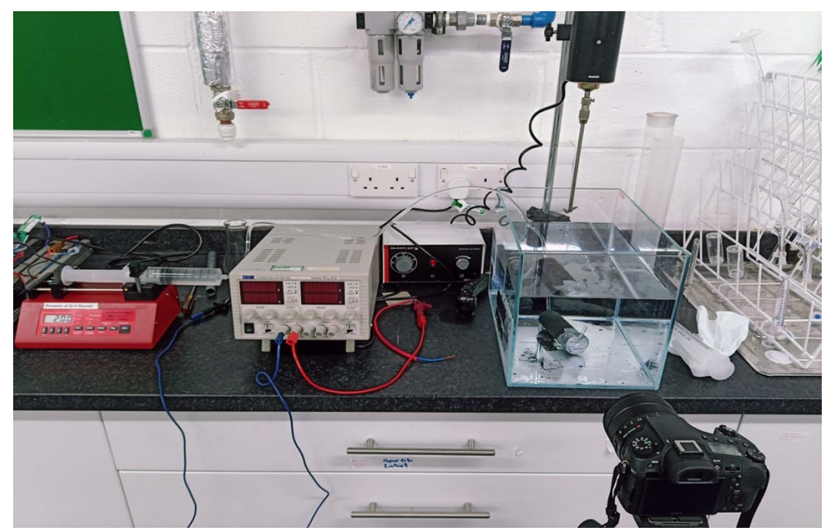

Fig. 8 Final experimental set-up

\section{Results}

PDT uses the shape of the curved interface to extract the interfacial tension of the droplet and does not require advanced instrumentation. The precision of the analysis is improved with the use of image analysis software to match the shape of the curve to Young-Laplace equation. The effect of electric field on the movement of the condensate droplet along the rise path is captured using the force analysis equation given in Eq. (8). The effect of electric field on the interfacial tension between the condensate droplet and the brine solution is captured using pendant drop tensiometry. As shown in Table 8 (see Appendix), the salinity and electric current were varied from 0-19.23ppt and 0-46.5 $\mathrm{V}$, respectively. The measurements for each parameter were obtained at least 12 times to satisfy statistical significance. Properties of the droplet and brine solution extracted from the experiment are presented in Table 3.

Based on the conditions of this experiment, a significant deviation of droplet trajectory is expected under the following conditions:

(i) Changes in the permittivity of the brine due to alterations in the salinity of the brine. Brine salinity would be altered if new ions are introduced at the electrodes during REDOX reactions. The probability of REDOX reaction occurring at the electrodes was minimized with the use graphite electrodes

(ii) Increase in polar components (acids and bases which are surface active) of the condensate droplets. This would occur if the composition of the condensate changes with time. An increase in polar component would increase the charge density around the droplet surface.

(iii) Temperature change caused by increase in electric voltage. Electrolysis is initiated when the voltage increases beyond a threshold value. Heat given off at the electrodes during electrolysis may cause a temperature rise within the brine. The resulting tem-

Table 3 Droplet data extracted from experiment

Key droplet parameters (obtained from experi- Values ment)

\begin{tabular}{ll}
\hline Volume of droplet, $V_{d}$ & $0.1046 \times 10^{-6} \mathrm{~m}^{3}$ \\
Brine density, $\rho_{b}$ & $1065.8 \mathrm{~kg} / \mathrm{m}^{3}$ \\
Reynolds number, Re & 0.2 \\
Condensate density, $\rho_{c}$ & $657 \mathrm{~kg} / \mathrm{m}^{3}$ \\
Pump volumetric flowrate, $Q_{p}$ & $0.033 \times 10^{-6} \mathrm{~m}^{3} / \mathrm{s}$ \\
Buoyancy force, $\mathrm{F}_{\mathrm{B}}$ & $0.00103 \mathrm{~N}$ \\
Pump pressure force, $F_{P}$ & $0.0000645 \mathrm{~N} / \mathrm{s}$ \\
Gravity force, $F_{G}$ & $0.000674 \mathrm{~N}$ \\
\hline
\end{tabular}


perature rise affects the buoyancy force acting on the droplet and causes a deviation. The maximum voltage applied across the electrodes was limited to 46.5 $\mathrm{V}$ to checkmate this occurrence

By minimizing or eliminated other potential sources of trajectory deviation, the experiment was designed to capture only deviations caused by varying electric voltage.

The droplet trajectory was extracted using the guidelines highlighted in Sect. 2.1. Deviations in the droplet trajectory as a function of electric voltage across the electrodes were recorded using the high-speed camera. For each droplet trajectory shown in Fig. 9, the droplet rise velocity, horizontal deviation, nominal distance ( $\mathrm{a}$ and $\mathrm{b}$ ) was measured, and the results presented in Tables 4, 5, 6, 7. Each droplet trajectory was measured 3 times. Details of the results obtained are captured in Appendix section.

During the experiment run-time, an average of 4 droplet rise is recorded; this brings total measurement for the behavior droplet at various voltages to 12 . A plot of the droplet trajectory properties is presented in Fig. 10. The droplet rising velocity was estimated by measuring the droplet travel distance against the time it takes for the droplet to rise from position A to position D. Results from the analysis shows that as the voltage increase, the droplet rise velocity decreases from the initial $140 \mathrm{~mm} / \mathrm{s}$ to a near constant value of $120 \mathrm{~mm} / \mathrm{s}$ at $26.5 \mathrm{~V}$. The change in trajectory of the droplet increases the travel time as voltage applied increases. True vertical distance to deviation indicates the kick-off point for the change in droplet trajectory. An increase in
Fig. 9 Extracted images of actual droplet paths (a) No Voltage (b) $5.25 \mathrm{~V}$ (c) $26.5 \mathrm{~V}$ (d) $46.5 \mathrm{~V}$
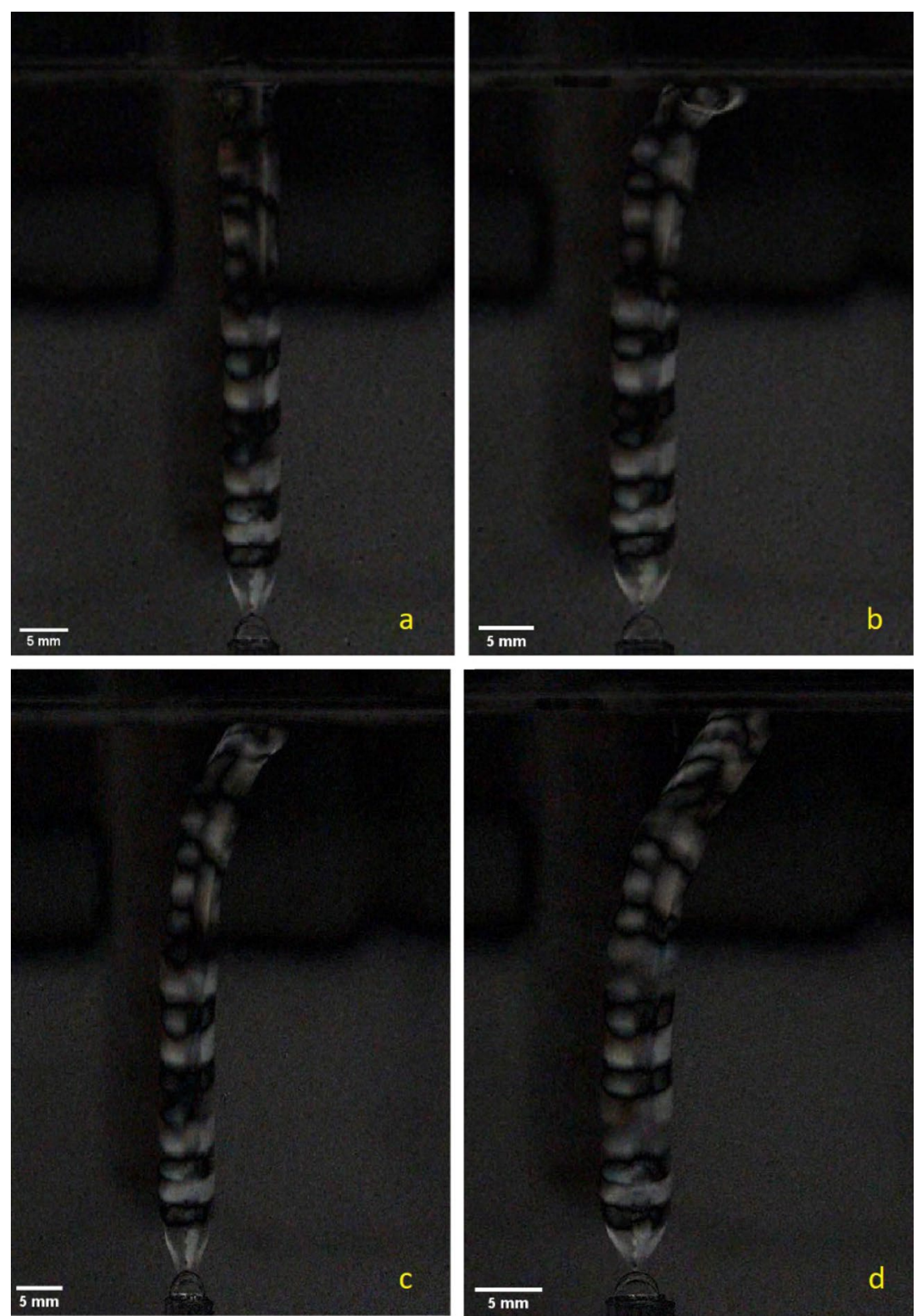
Table 4 Case a: Deionized water with no salt content and no DC current

\begin{tabular}{|c|c|c|c|c|}
\hline \multirow{2}{*}{$\begin{array}{l}\text { Voltage (V) } \\
\text { Reading }\end{array}$} & \multicolumn{4}{|c|}{ No Voltage } \\
\hline & \#1 & \#2 & \#3 & \#4 \\
\hline Horizontal deviation, $c$ & 0.000 & 0.000 & 0.000 & 0.000 \\
\hline True vertical distance to deviation, $d$ & 45.429 & 45.321 & 45.429 & 45.429 \\
\hline Droplet rise time, $t$ (secs) & 0.325 & 0.330 & 0.300 & 0.330 \\
\hline True vertical distance, $(a+d)$ & 45.429 & 45.429 & 45.429 & 45.429 \\
\hline Nominal distance, $a$ & 0.000 & 0.107 & 0.000 & 0.000 \\
\hline Lateral distance, $b(\mathrm{~mm})$ & 0.000 & 0.107 & 0.000 & 0.000 \\
\hline Droplet rise velocity, $v(\mathrm{~mm} / \mathrm{s})$ & 139.7802 & 137.6623 & 151.4286 & 137.6623 \\
\hline
\end{tabular}

Table 5 Case b: Salinity Constant, Low Voltage (5.26 V)

Table 6 Case c: Salinity Constant, Low Voltage (26.24 V)

Table 7 Case d: Salinity Constant, Low Voltage (46.57 V)

\begin{tabular}{lllll}
\hline Voltage $(\mathrm{V})$ & \multicolumn{4}{l}{ Low Voltage $(5.26 \mathrm{~V})$} \\
\cline { 2 - 5 } Reading & $\# 1$ & $\# 2$ & $\# 3$ & $\# 4$ \\
\hline Horizontal deviation, $c$ & 2.930 & 2.584 & 2.364 & 0.000 \\
True Vertical Distance to Deviation, $d$ & 40.000 & 39.291 & 40.756 & 45.429 \\
Droplet Rise Time, $t(\mathrm{secs})$ & 0.330 & 0.380 & 0.350 & 0.350 \\
True Vertical Distance, $(a+d)$ & 45.429 & 45.429 & 45.429 & 45.429 \\
Nominal Distance, $a(\mathrm{~mm})$ & 5.429 & 6.138 & 4.672 & 0.000 \\
Lateral distance, $b(\mathrm{~mm})$ & 7.333 & 6.339 & 5.236 & 0.000 \\
Droplet rise velocity, $v(\mathrm{~mm} / \mathrm{s})$ & 143.4326 & 120.0781 & 131.4074 & 129.7959 \\
\hline
\end{tabular}

\begin{tabular}{|c|c|c|c|c|}
\hline \multirow{2}{*}{$\begin{array}{l}\text { Voltage (V) } \\
\text { Reading }\end{array}$} & \multicolumn{4}{|c|}{ Mid Voltage (26.24 V) } \\
\hline & $\# 1$ & $\# 2$ & $\# 3$ & $\# 4$ \\
\hline Horizontal deviation, $\mathrm{c}$ & 3.877 & 4.161 & 4.776 & 4.066 \\
\hline True vertical distance to deviation, $d$ & 36.596 & 36.407 & 32.955 & 37.588 \\
\hline Droplet rise time, $t$ (secs) & 0.380 & 0.380 & 0.380 & 0.400 \\
\hline True vertical distance, $(a+d)$ & 45.429 & 45.429 & 45.429 & 45.429 \\
\hline Nominal distance, $a$ & 8.833 & 9.022 & 12.474 & 7.840 \\
\hline Lateral distance, $b(\mathrm{~mm})$ & 9.646 & 9.935 & 13.357 & 8.832 \\
\hline Droplet rise velocity, $v(\mathrm{~mm} / \mathrm{s})$ & 121.6898 & 121.9520 & 121.8725 & 116.0509 \\
\hline
\end{tabular}

\begin{tabular}{lllll}
\hline Voltage $(\mathrm{V})$ & \multicolumn{4}{l}{ High Voltage $(46.57)$} \\
\cline { 2 - 5 } Reading & $\# 1$ & $\# 2$ & $\# 3$ & $\# 4$ \\
\hline Horizontal deviation, $c$ & 8.511 & 8.038 & 7.860 & 8.558 \\
True vertical distance to deviation, $d$ & 22.749 & 26.820 & 27.518 & 28.274 \\
Droplet rise time, $t(\mathrm{secs})$ & 0.380 & 0.400 & 0.400 & 0.380 \\
True vertical distance, $(a+d)$ & 45.429 & 45.429 & 45.429 & 45.429 \\
Nominal distance, $a$ & 22.680 & 18.608 & 17.911 & 17.155 \\
Lateral distance, $b(\mathrm{~mm})$ & 24.224 & 20.270 & 19.559 & 19.171 \\
Droplet rise velocity, $v(\mathrm{~mm} / \mathrm{s})$ & 123.6127 & 117.7264 & 117.6937 & 124.8543 \\
\hline
\end{tabular}

voltage causes a corresponding decrease in the true vertical distance to deviation to reflect the increasing radius of impact.

The horizontal deviation $\mathrm{C}$ is the strongest measure of the effect of the electric field on the droplet path as it alters the otherwise vertical motion of the droplet due to buoyancy effect. From the result obtained, a temporary decrease was observed. This could be attributed to the random motion of brine immediately after mixing. Thereafter, a progressive increase in deviation is observed as the voltage is increased. 


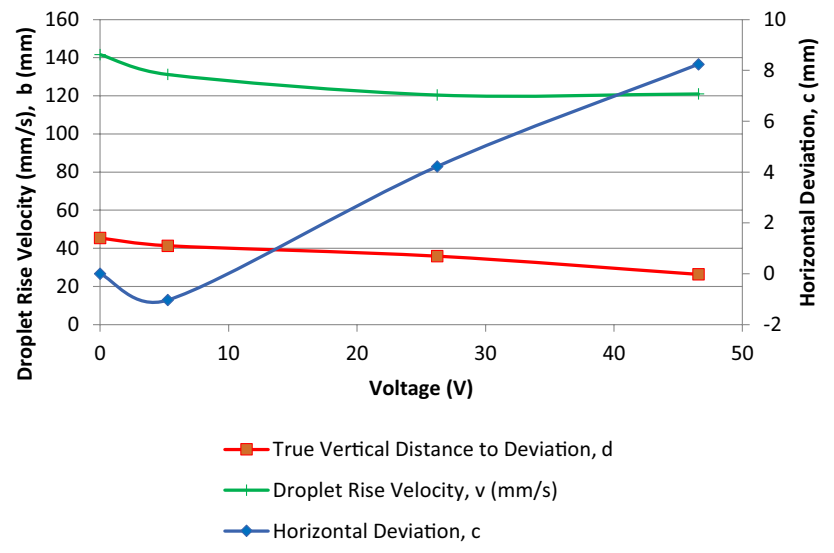

Fig. 10 Effect of voltage on droplet trajectory

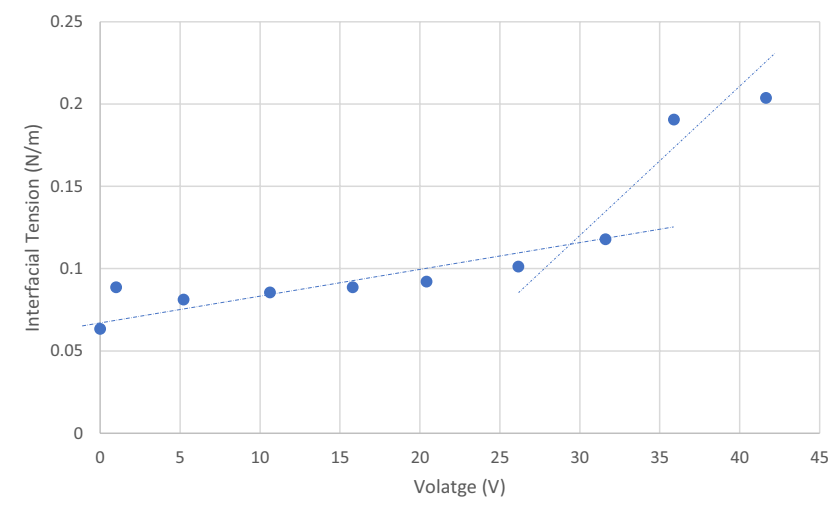

Fig. 11 A graphical plot of the effect of Electric voltage on Interfacial tension

Typically, during oil production, brine (low salinity) is used to drive the oil from the reservoirs into the production well. The ability to do this effectively depends on the interfacial tension acting between the brine and the oil molecules. A lower interfacial tension increases the oil displacement efficiency of the brine (Nicolini et al. 2017; Wagner and Leach 1966). Results from the interfacial tension (IFT) measurement obtained from the experiment reveal a progressive increase in IFT as the voltage is increased (see Fig. 11). This can be attributed to the distribution of electric charge across the droplet interface in the presence of the electric field. When the electric voltage is increased up to $26 \mathrm{~V}$, a significant increase in interfacial tension is observed. This increase is captured by a change in trendline.

\section{Experimental Error Reporting}

Two types of error are captured in this analysis: reading error and standard deviation error. The reading error accounts for the uncertainty in measurement observed from the highspeed camera. Three parameters were measured directly; true vertical distance to deviation (d), horizontal deviation (c), and droplet rise time. The droplet diameter, horizontal and vertical deviations were all subjected to a reading error of $\pm 0.05 \mathrm{~mm}$, while the droplet rise time (t) was subjected to a reading error of $\pm 0.005 \mathrm{~s}$. To account for the disparity in measured values, the standard deviation of each reading was estimated from the mean value. The standard deviation gives the error spread in the mean value of the readings obtained from the experiment. Using data given in Table 4, 5, 6, 7, the mean, standard deviation, and coefficient of variance were computed from Eqs. (12)-(14).

Mean, $\mu=\frac{\sum\left(x_{i}+x_{i+1}+\ldots x_{N}\right)}{N}$

Standard Deviation, $\sigma=\sqrt{\left[\frac{\sum\left(x_{i}-\mu\right)^{2}}{N}\right]}$

Coefficient of Variance $=\frac{\sigma}{\mu}$

where $N$-Number of input data, $x_{i}$-measured data.

\section{Error propagation}

The droplet rise velocity was analytically obtained from these parameters using Eq. (15). We observed that the reading error was relatively small compared to the standard deviations. For the error propagation, we made use of standard deviation.

$\operatorname{Droplet~Rise~Velocity~}(\mathrm{mm} / \mathrm{s})=\frac{d+\sqrt{\left(a^{2}+c^{2}\right)}}{t}$

Error Propagation $=\sqrt{\left(\sigma_{d}^{2}+\sigma_{a}^{2}+\sigma_{c}^{2}+\sigma_{t}^{2}\right)}$

where $a, d, c$ and $t$ are droplet trajectory parameters as shown in Fig. 4 and given in Tables 4, 5, 6, 7

$\sigma_{d}$-standard deviation for true vertical distance to deviation.

The results of the analysis for each voltage reading are presented in Figs. 12, 13, 14.

From the error analysis, it was observed that the coefficient of variation for all considered parameters did not exceed $10 \%$. This connotes that repeated measurements produced similar results with a $90 \%$ confidence interval. A progressive increase in error propagation of the droplet rise velocity was observed as the voltage is increased. This is expected because of the increase in lateral movement of the droplet observed when the volage is increase. 


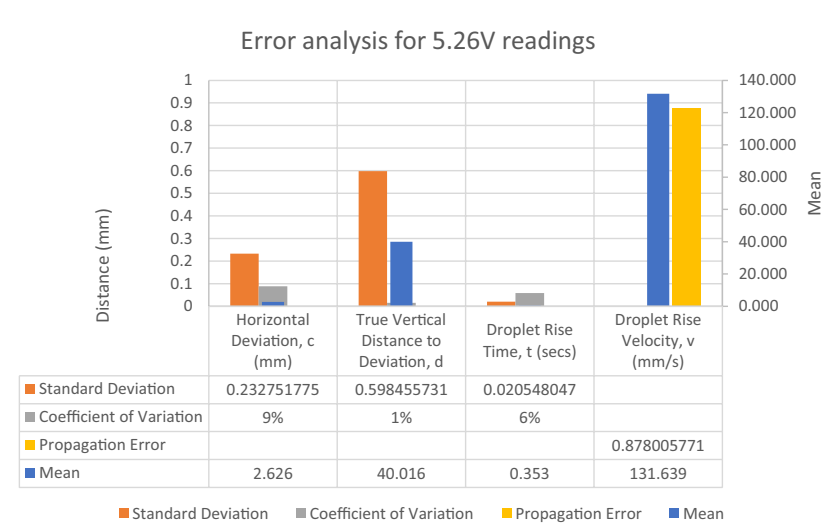

Fig. 12 Error analysis for $5.26 \mathrm{~V}$

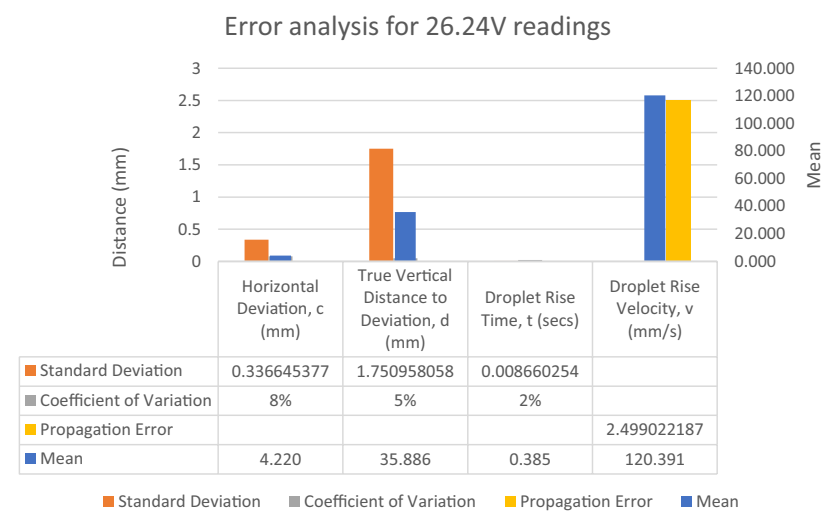

Fig. 13 Error analysis for $26.24 \mathrm{~V}$ readings

\section{Conclusion}

In this work, laboratory experiments to capture the effect of direct current on condensate droplets were performed. This provides insights into the behavior of condensate droplets in the pore space when DC current is introduced. Results obtained from previous laboratory experiments reveal that an increase in the current introduced into the hydrocarbon saturated cores, leads to a corresponding increase in condensate displacement efficiency until a certain threshold of

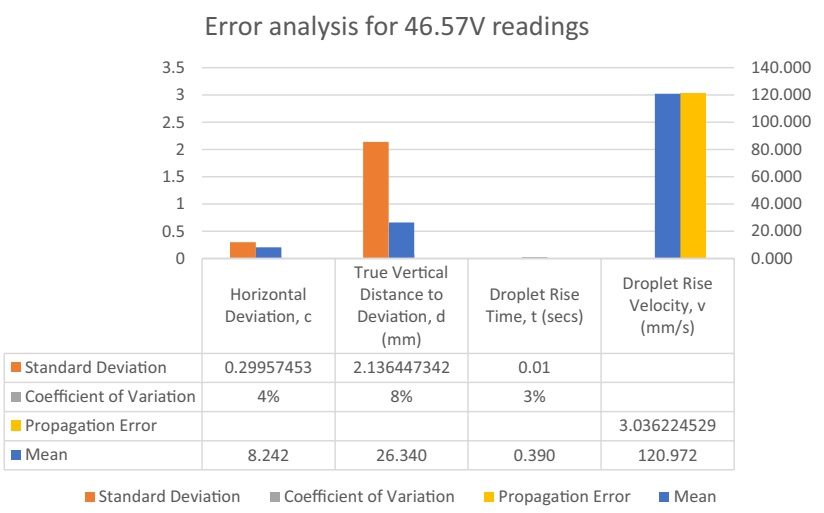

Fig. 14 Error analysis for $46.57 \mathrm{~V}$ readings

current is reached (Wentong Zhang et al. 2019a, b). The explanation for this was tied to the interaction between the direct current and rock surface via electromigration and electrophoresis (Ghosh et al. 2012; Paillat et al. 2000; Rahbar et al. 2018). The release of hydrogen ions and hydroxide ions during electrolysis at high voltage is thought to weaken the acidic environment of the pore space by combining to form water. However, insights from this experiment reveal that in the absence of rock surface, an increase in voltage leads to a preferential movement of the condensate droplet toward the anode and a corresponding increase in interfacial tension between the condensate droplet and brine solution. This shows that as DC current is increased, the interfacial tension increases progressively until its effect counteracts the benefit obtained from the preferential movement of condensate droplet. Temperature variation was not considered in this study because at reservoir conditions the temperature is fairly constant. However, for future investigations, the experiments should be conducted at elevated temperatures to capture the reservoir temperature conditions.

\section{Appendix}

See Table 8 


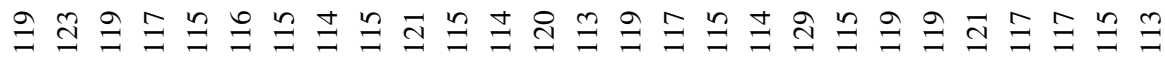

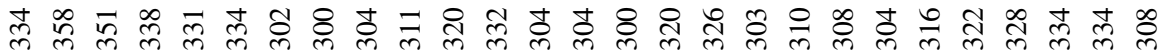

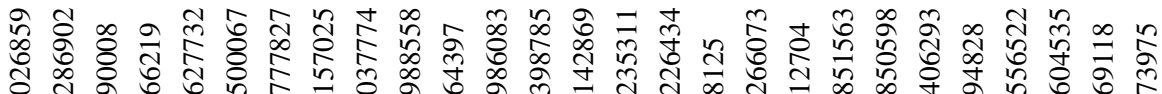

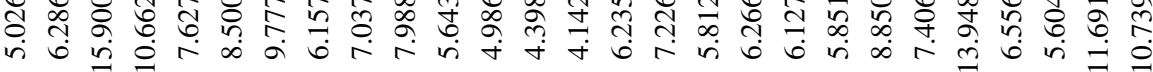

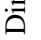

吉品

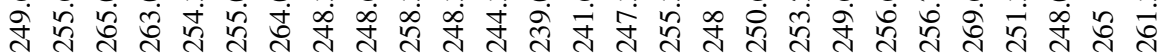

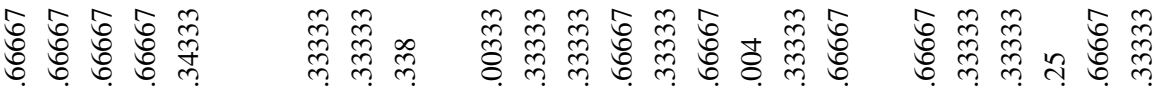

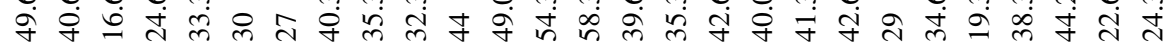

$\cong$

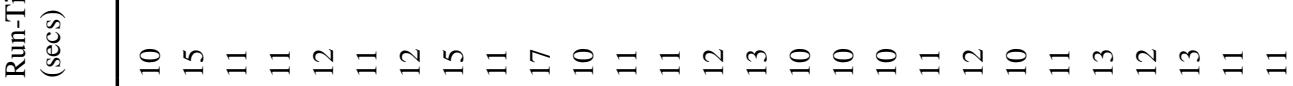

항 范 ○ 


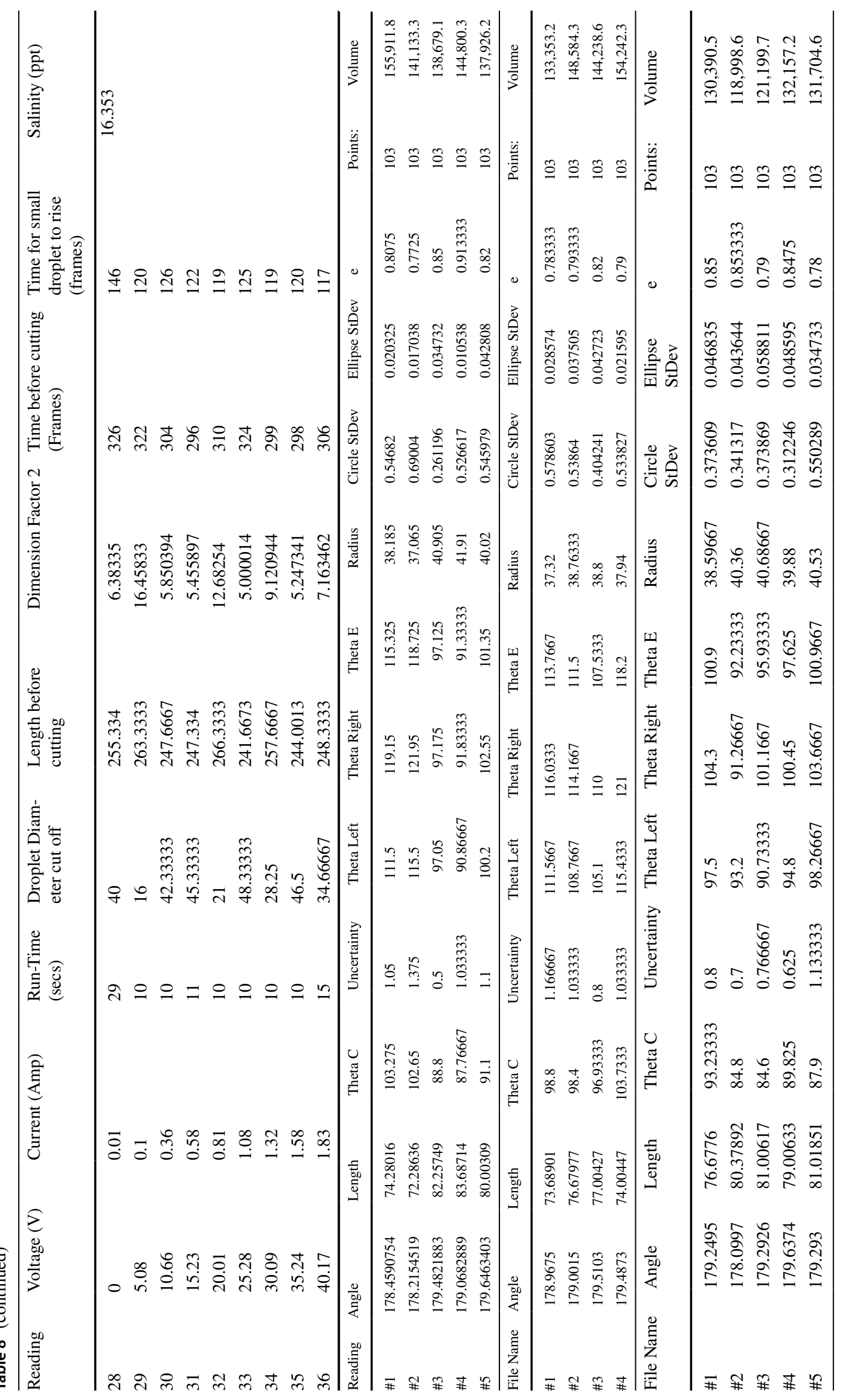


Acknowledgements The authors express their gratitude to Petroleum Technology Development Fund for providing funding vital to this research. The authors would like to specifically thank the team of senior technicians at Teesside University, Gary Atkinson, Kevin Mallam, Lawrence Jeff, and Morgan Guy, for their help in the setting up components used for this project.

Funding Funding for this project was received from Petroleum Technology Development Fund, under grant number PTDF/ED/PHD/ PPI/1028/17. The funders had no role in study design, data collection and analysis, decision to publish, or preparation of the manuscript.

\section{Declarations}

Conflict of interest The authors declare no conflict of interest on this work.

Open Access This article is licensed under a Creative Commons Attribution 4.0 International License, which permits use, sharing, adaptation, distribution and reproduction in any medium or format, as long as you give appropriate credit to the original author(s) and the source, provide a link to the Creative Commons licence, and indicate if changes were made. The images or other third party material in this article are included in the article's Creative Commons licence, unless indicated otherwise in a credit line to the material. If material is not included in the article's Creative Commons licence and your intended use is not permitted by statutory regulation or exceeds the permitted use, you will need to obtain permission directly from the copyright holder. To view a copy of this licence, visit http://creativecommons.org/licenses/by/4.0/.

\section{References}

Al-Anazl HA, Walker JG, Pope GA, Sharma MM, Hackney DF (2005) A successful methanol treatment in a gas/condensate reservoir: Field application. SPE Prod Facil 20(1):60-69. https://doi.org/ 10.2118/80901-pa

Almehaideb RA, Ashour I, El-Fattah KA (2003) Improved K-value correlation for UAE crude oil components at high pressures using PVT laboratory data. Fuel 82(9):1057-1065. https://doi.org/10. 1016/S0016-2361(03)00004-8

Ansari A, Haroun M, Motiur Rahman MV, Chilingar G, Sarma H (2017) A novel improved oil recovery approach for increasing capillary number by enhancing depth of penetration in abu dhabi carbonate reservoirs. Interdisc J Chem. https://doi.org/10.15761/ ijc. 1000117

Ansari A, Haroun M, Rahman MM, Chilingar GV (2015a) Assessing the environomic feasibility of electrokinetic low-cncentration acid IOR in Abu Dhabi carbonate reservoirs. SPE Oil and Gas India Conference and Exhibition. https://doi.org/10.2118/178124-ms

Ansari A, Haroun M, Rahman MM, Chilingar GV (2015b) Electrokinetic driven low-concentration acid improved oil recovery in $\mathrm{Abu}$ Dhabi tight carbonate reservoirs. Electrochim Acta 181:255-270. https://doi.org/10.1016/j.electacta.2015.04.174

Asar H, Handy LL (1989) Influence of interfacial tension on gas/oil relative permeability in a gas-condensate system. SPE Reserv Eng. 3(1):257-264. https://doi.org/10.2118/11740-pa

Ayub M, Ramadan M (2019) Mitigation of near wellbore gas-condensate by CO 2 huff-n-puff injection: a simulation study. J Petrol Sci Eng 175:998-1027. https://doi.org/10.1016/j.petrol.2018.12.066

Azari V, Abolghasemi E, Hosseini A, Ayatollahi S, Dehghani F (2018) Electrokinetic properties of asphaltene colloidal particles: Determining the electric charge using micro electrophoresis technique.
Colloids Surf, A 541(January):68-77. https://doi.org/10.1016/j. colsurfa.2018.01.029

Babadagli T (2007) Development of mature oil fields - A review. J Petrol Sci Eng 57(3-4):221-246. https://doi.org/10.1016/j.petrol. 2006.10.006

Barker JW (2005) Experience with simulation of condensate banking effects in various gas condensate reservoirs. International Petroleum Technology Conference, 1, pp 1-10. https://doi.org/10.2523/ IPTC-10382-MS

Behmanesh H, Hamdi H, Clarkson CR (2018) Reservoir and fluid characterization of a tight gas condensate well in the Montney Formation using recombination of separator samples and black oil history matching. J Nat Gas Sci Eng 49:227-240. https://doi. org/10.1016/j.jngse.2017.10.015

Berry JD, Neeson MJ, Dagastine RR, Chan DYC, Tabor RF (2015) Measurement of surface and interfacial tension using pendant drop tensiometry. J Colloid Interface Sci 454:226-237. https:// doi.org/10.1016/j.jcis.2015.05.012

Cameselle C, Gouveia S (2018) Electrokinetic remediation for the removal of organic contaminants in soils. Curr Opin Electrochem 11:41-47. https://doi.org/10.1016/j.coelec.2018.07.005

Canny J (1986) A computational approach to edge detection. IEEE Trans Pattern Anal Mach Intell PAMI-8(6):679-698. https://doi. org/10.1109/TPAMI.1986.4767851

Dang C, Nghiem L, Fedutenko E, Gorucu E, Yang C, Mirzabozorg A (2018) Application of artificial intelligence for mechanistic modeling and probabilistic forecasting of hybrid low salinity chemical flooding. https://doi.org/10.2118/191474-ms

Drelich J (2002) Measurement of Interfacial Tension in Fluid-Fluid Systems. Encyclopedia of Surface and Colloid Science, pp. 3152-3166

Fahimpour J, Jamiolahmady M (2014) Impact of gas-condensate composition and interfacial tension on oil-repellency strength of wettability modifiers. Energy Fuels. https://doi.org/10.1021/ ef5007098

Ferri JK, Fernandes PAL (2011) Axisymmetric drop shape analysis with anisotropic interfacial stresses: Deviations from the younglaplace equation. Bubble Drop Interfaces 1:61-74

Garmeh G, Johns RT, Lake LW (2009) Pore-scale simulation of dispersion in porous media. SPE J 14(4):559-567. https://doi.org/ 10.2118/110228-PA

Geiger S, Matthäi S, Niessner J, Helmig R (2009) Black-oil simulations for three-component, three-phase flow in fractured porous media. SPE J 14(2):338-354

Ghahri P (2010) Modelling of Gas-Condensate Flow around Horizontal and Deviated wells and Cleanup Efficiency of Hydraulically Fractured Wells (Doctoral thesis, Heriot-Watt University, Edinburgh, United Kingdom). Retrieved from http://hdl.handle.net/ $10399 / 2354$

Ghahri P, Jamiolahmadi M, Alatefi E, Wilkinson D, Sedighi Dehkordi F, Hamidi H (2018) A new and simple model for the prediction of horizontal well productivity in gas condensate reservoirs. Fuel 223:431-450. https://doi.org/10.1016/j.fuel.2018.02.022

Ghazanfari E, Shrestha RA, Miroshnik A, Pamukcu S (2012) Electrically assisted liquid hydrocarbon transport in porous media. Electrochim Acta 86:185-191. https://doi.org/10.1016/j.electacta. 2012.04.077

Ghosh B, Al Shalabi EW, Haroun M (2012) The effect of DC electrical potential on enhancing sandstone reservoir permeability and oil recovery. Pet Sci Technol 30(20):2148-2159. https://doi.org/10. 1080/10916466.2010.551233

Gregersen CS, Kazempour M, Alvarado V (2013) ASP design for the Minnelusa formation under low-salinity conditions: Impacts of anhydrite on ASP performance. Fuel 105:368-382. https://doi. org/10.1016/j.fuel.2012.06.051 
Haroun MR, Chilingar GV, Pamukcu S, Wittle JK, Belhaj H, Al Bloushi MN (2009) Optimizing electroosmotic flow potential for electrically enhanced oil recovery (EEORTM) in carbonate rock formations of Abu Dhabi based on rock properties and composition. Int Petrol Technol Conf, Dc. https://doi.org/10.2523/ IPTC-13812-MS

Hassan A, Mahmoud M, Al-Majed A, Alawi MB, Elkatatny S, BaTaweel M, Al-Nakhli A (2019) Gas condensate treatment: A critical review of materials, methods, field applications, and new solutions. J Petrol Sci Eng 177:602-613. https://doi.org/10.1016/j. petrol.2019.02.089

Hekmatzadeh M, Gerami S (2018) A new fast approach for well production prediction in gas-condensate reservoirs. J Petrol Sci Eng 160:47-59. https://doi.org/10.1016/j.petrol.2017.10.032

Hill D (2014) Application of electrokinetics for enhanced oil recovery. In: Chilingar GV, Haroun M (eds) Electrokinetics for petroleum and environmental engineers. Wiley, New York, pp 103-155. https://doi.org/10.1002/9781118842805.ch3

Hoteit H (2013) Modeling diffusion and gas-oil mass transfer in fractured reservoirs. J Petrol Sci Eng 105:1-17. https://doi.org/10. 1016/j.petrol.2013.03.007

Ikpeka P, Ugwu J, Russell P, Pillai G (2020) Performance evaluation of machine learning algorithms in predicting dew point pressure of gas condensate reservoirs. SN Appl Sci. https://doi.org/10.1007/ s42452-020-03811-x

Karbaschi M, Taeibi Rahni M, Javadi A, Cronan CL, Schano KH, Faraji S, Won JY, Ferri JK, Krägel J, Miller R (2015) Dynamics of drops-Formation, growth, oscillation, detachment, and coalescence. Adv Coll Interface Sci 222:413-424. https://doi.org/10. 1016/j.cis.2014.10.009

Kelbaliyev G, Ceylan K (2007) Development of new empirical equations for estimation of drag coefficient, shape deformation, and rising velocity of gas bubbles or liquid drops. Chem Eng Commun 194(12):1623-1637. https://doi.org/10.1080/00986440701446128

Kester DR, Duedall IW, Connors DN, Pytkowicz RM (1967) Department of Zoology and Plankton Laboratory, University of Southampton, England. Limnol Oceanogr 12:176-179

Loglio G, Pandolfini P, Liggieri L, Makievski AV, Ravera F (2011) Determination of interfacial properties by the pendant drop tensiometry: Optimisation of experimental and calculation procedures. Bubble Drop Interfaces. https://doi.org/10.1163/ej.9789004174 955.i-558.12

Louli V, Pappa G, Boukouvalas C, Skouras S, Solbraa E, Christensen KO, Voutsas E (2012) Measurement and prediction of dew point curves of natural gas mixtures. Fluid Phase Equilib 334:1-9. https://doi.org/10.1016/j.fluid.2012.07.028

Majidi SMJ, Shokrollahi A, Arabloo M, Mahdikhani-Soleymanloo R, Masihi M (2014) Evolving an accurate model based on machine learning approach for prediction of dew-point pressure in gas condensate reservoirs. Chem Eng Res Des 92(5):891-902. https://doi. org/10.1016/j.cherd.2013.08.014

Mohammadi H, Sedaghat MH, Khaksar Manshad A (2013) Parametric investigation of well testing analysis in low permeability gas condensate reservoirs. J Nat Gas Sci Eng 14:17-28. https://doi. org/10.1016/j.jngse.2013.04.003

Mokhtari R, Varzandeh F, Rahimpour MR (2013) Well productivity in an Iranian gas-condensate reservoir: A case study. J Nat Gas Sci Eng 14:66-76. https://doi.org/10.1016/j.jngse.2013.05.006

Nicolini JV, Ferraz HC, Borges CP (2017) Effect of seawater ionic composition modified by nanofiltration on enhanced oil recovery in Berea sandstone. Fuel 203:222-232. https://doi.org/10.1016/j. fuel.2017.04.120

Novak N, Louli V, Skouras S, Voutsas E (2018) Prediction of dew points and liquid dropouts of gas condensate mixtures. Fluid
Phase Equilib 457:62-73. https://doi.org/10.1016/j.fluid.2017. 10.024

Odi U, El Hajj H, Gupta A (2012) Experimental investigation of wet gas dew point pressure change with carbon dioxide concentration. Society of Petroleum Engineers-Abu Dhabi International Petroleum Exhibition and Conference 2012, ADIPEC 2012-Sustainable Energy Growth: People, Responsibility, and Innovation, 3, 1632-1650. https://doi.org/10.2118/161478-ms

Paillat T, Moreau E, Grimaud PO, Touchard G (2000) Electrokinetic phenomena in porous media applied to soil decontamination. IEEE Trans Dielectr Electr Insul 7(5):693-704. https://doi.org/ 10.1109/94.879363

Peraki M, Ghazanfari E, Pinder GF (2018) Numerical investigation of two-phase flow encountered in electrically enhanced oil recovery. J Petrol Explor Prod Technol 8(4):1505-1518. https://doi.org/10. 1007/s13202-018-0449-0

Rahbar M, Pahlavanzadeh H, Ayatollahi S, Manteghian M (2018) Predicting the rock wettability changes using solutions with different $\mathrm{pH}$, through streaming potential measurement. J Petrol Sci Eng 167:20-27. https://doi.org/10.1016/j.petrol.2018.03.080

Rahimzadeh A, Bazargan M, Darvishi R, Mohammadi AH (2016) Condensate blockage study in gas condensate reservoir. J Nat Gas Sci Eng 33:634-643. https://doi.org/10.1016/j.jngse.2016.05.048

Rehman MM, Meribout M (2012) Conventional versus electrical enhanced oil recovery: a review. J Petrol Explor Prod Technol 2(4):169-179. https://doi.org/10.1007/s13202-012-0035-9

Rossen WR, Zhou ZH, Mamun CK (1995) Modeling foam mobility in porous media. SPE Advanced Technology Series 3(01):337-351

Sayed MA, Al-Muntasheri GA (2016) Mitigation of the effects of condensate banking: a critical review. SPE Prod Oper 31(2):85-102. https://doi.org/10.2118/168153-pa

Skylogianni E, Novak N, Louli V, Pappa G, Boukouvalas C, Skouras S, Solbraa E, Voutsas E (2015) Measurement and prediction of dew points of six natural gases. Fluid Phase Equilib 424:8-15. https:// doi.org/10.1016/j.fluid.2015.08.025

Stauffer CE (1965) The measurement of surface tension by the pendant drop technique. J Phys Chem 69(6):1933-1938. https://doi.org/ 10.1021/j100890a024

Tang G-Q, Morrow NR (1999) Influence of brine composition and fines migration on crude oil/brine/rock interactions and oil recovery. J Petrol Sci Eng 24(2-4):99-111. https://doi.org/10.1016/S09204105(99)00034-0

Thomas FB, Bennion DB, Andersen G (2009) Gas Condensate Reservoir Performance. J Can Pet Technol 48(07):18-24. https://doi. org/10.2118/09-07-18

van Dijke MIJ, Sorbie KS (2003) Pore-scale modelling of three-phase flow in mixed-wet porous media: Multiple displacement chains. J Petrol Sci Eng 39(3-4):201-216. https://doi.org/10.1016/S09204105(03)00063-9

Wagner OR, Leach RO (1966) Effect of Interfacial Tension on Displacement Efficiency. Soc Petrol Eng J 6(04):335-344. https:// doi.org/10.2118/1564-pa

Williams JK, Dawe RA (1989) Near-critical condensate fluid behavior in porous media- a modeling approach. SPE Reservoir Eng (soc Petrol Eng) 4(2):221-227

Wittle JK, Hill DG, Chilingar GV (2011) Direct electric current oil recovery (EEOR)-A new approach to enhancing oil production. Energy Sour, Part a: Recover, Util Environ Eff 33(9):805-822. https://doi.org/10.1080/15567036.2010.514843

Yim Y, Haroun MR, Al Kobaisi M, Sarma HK, Gomes JS, Rahman MM (2017, November 13) Experimental Investigation of Electrokinetic Assisted Hybrid Smartwater EOR in Carbonate Reservoirs. Abu Dhabi International Petroleum Exhibition \& Conference. https://doi.org/10.2118/188267-MS 
Zhang W, Cui Y, Jiang R, Xu J, Qiao X, Jiang Y (2019) Production performance analysis for horizontal wells in gas condensate reservoir using three-region model. J Nat Gas Sci Eng 61(61):226-236

Zhang W, Ning Z, Zhang B, Wang Q, Cheng Z, Huang L, Qi R, Shang $X$ (2019) Experimental investigation of driving brine water for enhanced oil recovery in tight sandstones by DC voltage. J Petrol Sci Eng 180(April):485-494. https://doi.org/10.1016/j.petrol. 2019.05.068 